\title{
Socioeconomic determinants of outpatient antibiotic use in Europe
}

\author{
Giuliano Masiero • Massimo Filippini • \\ Matus Ferech $\cdot$ Herman Goossens
}

Received: 25 May 2009/Revised: 22 March 2010/Accepted: 2 June 2010/Published online: 7 July 2010

(C) The Author(s) 2010. This article is published with open access at Springerlink.com

\begin{abstract}
Objectives Outpatient antibiotic consumption widely varies across Europe. The investigation of the causes of such variation may help to identify interventions that would improve the efficient use of antibiotics. The aim of this study was to assess the impact of socioeconomic determinants and the role played by information about bacterial resistance.

Methods Comparable data on systemically administered antibiotics and socioeconomic determinants in 17 European countries were available between 2000 and 2005. We estimated an ad hoc econometric model by means of a hybrid log-log functional form and random effects generalised least squares regressions. Lagged values and the instrumental variable method were applied to address endogeneity of bacterial resistance and infections. Bacterial resistance was measured by the rate of penicillin non-
\end{abstract}

\section{G. Masiero $(\square)$}

Department of Economics and Technology Management, University of Bergamo, Bergamo, Italy

e-mail: giuliano.masiero@lu.unisi.ch

\section{G. Masiero · M. Filippini}

Department of Economics, University of Lugano, Lugano, Switzerland

\section{Filippini}

ETH Zurich, Zurich, Switzerland

M. Ferech · H. Goossens

Laboratory of Medical Microbiology,

Vaccine and Infectious Diseases Institute,

University of Antwerp, Antwerp, Belgium

M. Ferech

Enterprise and Industry DG, Pharmaceuticals Unit,

European Commission, Brussels, Belgium susceptible Streptococcus pneumoniae isolates (PNSP) and methicillin-resistant Staphylococcus aureus (MRSA).

Results The population income, demographic structure, density of general practitioners and their remuneration method appeared to be significant determinants of antibiotic consumption. Although countries with higher levels of bacterial resistance exhibited significantly higher levels of per capita antibiotic use, ceteris paribus, the responsiveness of antibiotic use to changes in bacterial resistance was relatively low (0.09-0.18).

Conclusions The study confirms that socioeconomic factors should be taken into account while explaining differences in outpatient antibiotic use across countries. The impact of supply-side factors and incentives attached to payment schemes for physicians need to be considered in government interventions to reduce inequalities and improve effectiveness in antibiotic utilisation.

Keywords Antibiotic use - Cross-country variations · Bacterial resistance $\cdot$ Socioeconomic inequalities

\section{Introduction}

The market for antibiotics is characterised by multiple imperfections. Above all, antibiotic use may contribute to widespread bacterial resistance (Elbasha 2003), which still represents a challenge to achieving sustainable health for all by the year 2100 (Butler 2008). Antibiotic resistance leads to the production of newer and more effective generations of drugs, thus raising the costs for society (McGowan 2001).

Although antibiotic prescriptions have slightly decreased during the 1990s and have been roughly stable in recent years, prescribing practices still vary widely across 
countries (Elsevier et al. 2007). Mean figures of defined daily doses per 1,000 inhabitants (DID) for 21 European countries participating in the European Surveillance of Antimicrobial Consumption (ESAC) project and able to provide comparable and reliable data for at least 7 years between 1997 and 2005 show that France (31.55 DID), Greece (29.67 DID) and Spain (27.31 DID), amongst others, exhibit significantly higher values of antibiotic use than Austria (12.47 DID), Denmark (13.08 DID) and the Netherlands (10.00 DID) (see Fig. 1).

The investigation of the causes of such variation may help to identify sources of inefficiency in the use of antibiotics. As recommended by the WHO Commission on Social Determinants of Health, the measurement and the understanding of the problem of inequalities in health and health-care utilisation is a crucial one. The literature is rich in studies on socioeconomic determinants of inequalities in health and health-care utilisation (Kunst 2009). Nevertheless, we are not aware of any multifactorial analyses of socioeconomic determinants of outpatient antibiotic use at the European level.

Previous studies on socioeconomic determinants of antibiotic consumption have rather focused on regional variations within a country (Matuz et al. 2006). This paper takes a cross-country perspective and tries to assess whether the impact of determinants of antibiotic use at the country level, investigated in previous studies, can be generalised to the European level. Comparable data on outpatient antibiotic use and bacterial resistance across European countries have only recently become available
(Goossens et al. 2005) and the impact of information on bacterial resistance, together with other factors, has not been previously investigated.

The knowledge of overall levels of bacterial resistance within a country is likely to be shared by health-care providers. In several countries, guidelines on antibiotic treatment and information on routine tests concerning bacterial resistance are issued by hospitals or local health authorities every year or every 2 years. Guidelines are available to general practitioners in the area. This may convey the idea that bacterial resistance is an indicator of the effectiveness of antibiotic treatment. If doctors and patients are concerned about resistance externalities, higher levels of bacterial resistance will induce them to use antibiotics more carefully. However, if bacterial resistance is relatively high, increasing rates of antibiotic use may be required to overcome the reduced effectiveness of antibiotics. Although physicians eventually switch to newer antibiotics, several antibiotic therapies may be prescribed before finding the effective one. Consequently, doctors may prescribe antibiotics in accordance with existing information, but the future (social) costs of bacterial resistance may be underestimated.

This study proposes an econometric model to investigate the determinants of outpatient antibiotic use in Europe. Since the interaction between socioeconomic determinants of consumption and information on bacterial resistance is simultaneously taken into account and the impact of each single determinant is assessed, we argue that the approach can provide an indirect assessment of the effectiveness of
Fig. 1 Outpatient antibiotic use in Europe by country and year [in DID = defined daily doses (DDD) per 1,000 inhabitants per day]. Data source: European Surveillance of Antimicrobial Consumption, Antwerp, projects ESAC-1 (2001-2004) and ESAC-2 (2004-2007)

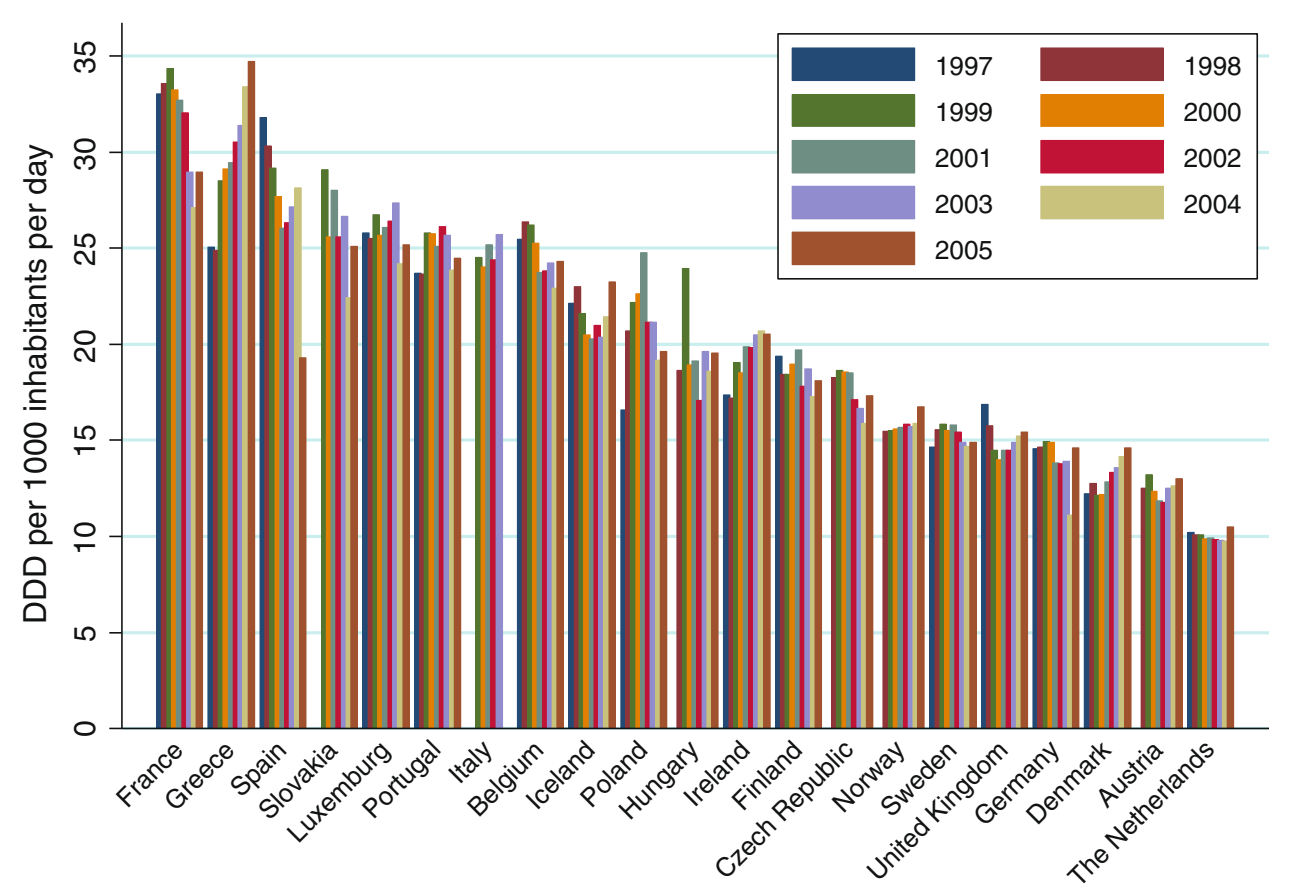


policies implemented across Europe between 2000 and 2005 to control antibiotic use and, consequently, to reduce the social impact of endogenous bacterial resistance.

\section{Methods}

Our approach for the investigation of determinants of antibiotic use in Europe consisted of specifying an econometric model using a set of covariates suggested by literature. This method was applied, for instance, by Di Matteo (2005) to investigate the macro-determinants of health expenditure in the USA and Canada. Multiple regression models were also recently employed to explore the association between socioeconomic factors and healthrelated aspects, such as the prevalence of substance use (İlhan et al. 2009) and the use of antibiotics within countries (Filippini et al. 2009a). Amongst determinants of antibiotic use, literature has underlined the patient education level, expectations of physicians and patients, cultural aspects, regulatory practice, and antibiotic price (Belongia and Schwartz 1998; Cockburn and Pit 1997; Finch et al. 2004).

We defined a consumption function for outpatient antibiotic use in Europe, which depended on the health status of the individuals, patients' attitudes towards the use of drugs, antibiotic price and the characteristics of health-care supply, such as physician density, physicians' remuneration scheme and information on the level of bacterial resistance. Socioeconomic variables, such as income and education, were considered in the model as proxies for the individual's stock of health, together with mortality for infectious diseases, which is difficult to measure. Researchers generally suggest that the educational level is a stable indicator of socioeconomic status across age and over time and may reflect individual's opportunities better than income (Hoogendijk et al. 2008). Therefore, our model served as a reduced form that considered both demand and supply factors.

The country represented the unit of our analysis. The per capita consumption of outpatient antibiotics was specified by the following parsimonious model:

$$
\begin{aligned}
\mathrm{DID}_{i t}= & f\left(Y_{i t}, \mathrm{DPH}_{i t}, \mathrm{POP}_{j i t}, \mathrm{EDU}_{i t}, \mathrm{EMPW}_{i t}, \mathrm{REG}_{h i},\right. \\
& \left.\mathrm{PGP}_{k i t}, P_{i t}, \mathrm{DCOP}_{i t}, \mathrm{INF}_{i t}, \mathrm{RES}_{i t}\right)
\end{aligned}
$$

where DID $_{i t}$ is the per capita antibiotic use in country $i$ and year $t$, as measured by the defined daily doses per 1,000 inhabitants collected by the European Surveillance of Antimicrobial Consumption. The standard dose is defined by the World Health Organization. Data were available for 21 European countries between 1997 and 2005. These data were reliable and exhibited a good degree of comparability, since the ESAC network screened for detection of bias in sample and census data, bias by over-the-counter sales and parallel trade, errors in assigning medicinal product packages to the Anatomical Therapeutic Chemical Classification (ATC), and errors in calculations of defined daily doses (Vander Stichele et al. 2004).

In Eq. $1, Y_{i t}$ is the per capita national income, $\mathrm{DPH}_{i t}$ is the physician density, $\mathrm{POP}_{1 i t}$. $\mathrm{POP}_{5 i t}$ indicate the percentage of the population below 14, between 15 and 24, 25 and 64, 65 and 79, and over 80 years. $\mathrm{EDU}_{i t}$ is the percentage of individuals (25-64 years) with at least upper secondary education. Cultural aspects that may influence antibiotic use were obtained by considering women participation in the labour market $\left(\mathrm{EMPW}_{i t}\right)$. A geographical dummy variable $\left(\mathrm{REG}_{h i}\right)$ that takes into account similarities with adjacent countries was also included. We divided countries into four groups: "north" $\left(\mathrm{REG}_{n i}=1\right)$, "south" $\left(\operatorname{REG}_{s i}=1\right)$, "east" $\left(\operatorname{REG}_{e i}=1\right)$, and "west", i.e. the reference group. The choice of the reference group does not have an effect on the model. The "west" group includes countries at the centre of Europe (Austria, Luxemburg, The Netherlands, Belgium, Germany and France) and the impact of the other three groups was measured relative to the comparison group.

We considered three main schemes of remuneration for general practitioners: fee for service, capitation and salary (Donaldson et al. 2004). We classified countries according to these schemes. Two dummy variables, $\mathrm{PGP}_{1 i t}$ and $\mathrm{PGP}_{2 i t}$, were introduced to capture the type of remuneration. If doctors were paid a fee per service, then PGP $_{1 i t}$ was equal to 1 . Conversely, if doctors worked under a salary regime, then $\mathrm{PGP}_{2 i t}$ was 1 . Finally, when both variables were 0 , the country used a capitation scheme. As a consequence, we interpreted the coefficient of $\mathrm{PGP}_{1 i t}$ as the effect of a fee-for-service remuneration scheme, and the coefficient of $\mathrm{PGP}_{2 i t}$ as the impact of a salary scheme.

$\mathrm{P}_{i t}$ is the price level for a defined daily dose of antibiotics. In several countries, insured patients offset some of the cost of care with copayments. Low copayments are intended to discourage individuals from using antibiotics unless when necessary. To capture the effect of copayment, we introduced a dummy variable $\left(\mathrm{COP}_{i t}\right)$. Full out-ofpocket $\mathrm{COP}_{i t}$ was equal to 1 . Conversely, when patients were fully or partially reimbursed, $\mathrm{COP}_{i t}$ was 0 .

Finally, $\mathrm{INF}_{i t}$ and $\mathrm{RES}_{i t}$ capture the impact of infections and the rate of bacterial resistance. We used mortality rates for infectious diseases as a proxy for the incidence of bacterial infections, since other indicators were less exhaustive and less reliable. One can see the level of bacterial resistance generated by antibiotic use as an additional economic cost of treatment for the whole community, since it reduces antibiotic effectiveness. Since the impact of infectious diseases and bacterial resistance may be endogenous (Thomas 1987), the estimation procedure of Eq. 1 addressed this problem, as it will be explained later. 
Regional and national policies towards antibiotics may also impact on consumption, but standard doses are unlikely to be affected. Unfortunately, comprehensive and reliable data on policies for the whole period 1997-2005 and for all our countries were not available. We assumed that the influence of policies could be neglected or the impact of policies was similar across countries over the observed period. The characteristics of national and regional campaigns in high-income countries were not identified and reviewed until very recently (Huttner et al. 2010). There was evidence that campaigns that were formally evaluated had an impact on antibiotic use.

The estimation of Eq. 1 required the specification of a functional form. Several alternative forms could be considered, since the theory (Thomas 1987) was quite ambiguous regarding this issue. Generally, the log-log specification offers an appropriate functional form for investigating the responsiveness of antibiotic use to changes in explanatory variables. The major advantage is that the estimated coefficients can be interpreted as elasticities, which are, therefore, assumed to be constant. Consequently, coefficients represent the percentage change in the value of the explained variable corresponding to a $1 \%$ variation in the value of the explanatory variable. However, the log transformation was not applied to dummy variables. Thus, we used a hybrid log-log functional form. Equation 1 was then specified as follows:

$$
\begin{aligned}
\operatorname{lnDID}_{i t}= & \beta_{0}+\beta_{1} \ln Y_{i t}+\beta_{2} \ln \mathrm{DPH}_{i t}+\sum_{j=3}^{6} \beta_{j} \ln \mathrm{POP}_{j i t} \\
& +\beta_{7} \ln \mathrm{EDU}_{i t}+\beta_{8} \ln \mathrm{EMPW}_{i t}+\sum_{k=9}^{11} \beta_{k} \mathrm{REG}_{k i} \\
& +\sum_{h=12}^{13} \beta_{h} \mathrm{PGP}_{h i t}+\beta_{14} \ln P_{i t}+\sum_{l=15}^{16} \beta_{l} \mathrm{DCOP}_{l i t} \\
& +\beta_{17} \ln \mathrm{INF}_{i t}+\beta_{18} \ln \mathrm{RES}_{i t}+v_{i}+\varepsilon_{i t},
\end{aligned}
$$

where $\ln ()$ is a natural logarithm applied to the variable and $v_{i}$ and $\varepsilon_{i t}$ are error terms with standard distribution assumptions.

Although data on antibiotic consumption were available for 21 European countries over 9 years, information on mortality for infectious diseases, bacterial resistance and price of pharmaceuticals was available for 17 countries only (Belgium, Greece, Poland and Slovakia were dropped). Moreover, information was not available for all the years. The final data set was an unbalanced panel data set with 81 observations. It is worth noticing that in one of the three models proposed (Model 2), we gained two observations since data on mortality rates improved information available for some countries in 2005. Regressions were performed by means of the statistical software STATA (version SE 10.1).
With regard to the choice of the econometric technique, it should be noted that in the econometric literature we can find various types of models focusing on cross-sectional variations over time, i.e. heterogeneity across units and periods. The most widely used approaches are the fixedeffects model and the random-effects model. For a detailed presentation of the econometric methods used to analyse panel data, see Greene (2003) and Baltagi (2005).

To choose the econometric approach, it was important to consider that our data set was a panel characterised by a relatively small number of time periods as well as relatively small number of cross-sectional units. Moreover, the within variation of the majority of the variables included in the model was relatively low. In this case, as suggested by Cameron and Trivedi (2005), the use of the fixed-effects model could imply a low statistical efficiency of the estimated parameters. Therefore, we focused on randomeffects generalised least squares regressions (Model 1).

However, since bacterial infections and resistance are plausibly endogenous (Thomas 1987), the estimation of Eq. 2 may lead to biased results. To tackle this problem, we adopted two alternative approaches: the inclusion of lagged values (Model 2) and the instrumental variable method (Model 3). In Model 2, instead of $\mathrm{INF}_{i t}$ we used $\mathrm{INF}_{i t-1}$ (the lagged mortality rate for infectious diseases), and instead of $\mathrm{RES}_{i t}$ we used RES ${ }_{i t-1}$ (the lagged rate of bacterial resistance).

For the instrumental variables approach, we considered some variables related to the spread process of infections. The density of the population and the size of a country may plausibly contribute to the spread of infections. Levels of bacterial resistance may be related to the extensive use of antibiotics in agriculture and animal breeding. As an example, Campylobacter is the most frequently reported zoonotic pathogen to cause human illnesses, and resistant bacteria tend to be harboured in the meat produced (Swiss National Science Foundation 2007). The common practice of using milk produced during antibiotic treatment for feeding calves and the meat of pigs causes a marked selection for resistant bacterial strains (i.e. enterococci), which may enter the food chain. Thus, we specified a model (Model 3) by instrumenting the rate of bacterial resistance and the mortality from infectious diseases with the production of milk and meat of pigs, the use of fertilisers in agriculture, the density of the population and the country area. In this case, a two-stage least squares technique with random effects was applied.

The annual data available on the determinants of outpatient antibiotic use between 1997 and 2005 are summarised in Table 1. These include socioeconomic characteristics of the population (income, demographic structure, education and participation in labour market, and regional clusters), supply-side factors (density of doctors 
Table 1 Variables notation and summary statistics

\begin{tabular}{|c|c|c|c|c|c|}
\hline Description & Variables & Mean & SD & Minimum & Maximum \\
\hline Outpatient antibiotic consumption & DDDs per 1,000 inhabitants per day (DID) & 20.30 & 6.18 & 9.75 & 34.72 \\
\hline Income per capita & GDP in PPP/population (Y) & 25,926 & 9,747 & 8,898 & 70,600 \\
\hline Antibiotic price & $\begin{array}{l}\text { Comparative price levels for } \\
\text { pharmaceutical products }(\mathrm{P})\end{array}$ & 93.29 & 23.75 & 36.65 & 160.00 \\
\hline \multirow[t]{5}{*}{ Demographic structure of population } & Population under 14/population $\left(\mathrm{POP}_{1}\right)$ & 17.90 & 2.27 & 14.10 & 24.00 \\
\hline & Population 15-24/population $\left(\mathrm{POP}_{2}\right)$ & 13.41 & 1.89 & 10.40 & 17.50 \\
\hline & Population 25-64/population $\left(\mathrm{POP}_{3}\right)$ & 53.67 & 1.94 & 47.90 & 57.70 \\
\hline & Population 65-79/population $\left(\mathrm{POP}_{4}\right)$ & 11.53 & 1.49 & 8.50 & 14.70 \\
\hline & Population over 80/population $\left(\mathrm{POP}_{5}\right)$ & 3.45 & 0.80 & 1.80 & 5.40 \\
\hline Attainment of high education & $\begin{array}{l}\text { Population with upper secondary } \\
\text { education/total population (EDU) }\end{array}$ & 66.18 & 16.91 & 17.80 & 89.90 \\
\hline Women participation in the labour market & Women employement rate (EMPW) & 56.39 & 12.58 & 15.99 & 81.20 \\
\hline Density of doctors & Practices/1,000 inhabitants (DPH) & 3.14 & 0.61 & 1.90 & 4.90 \\
\hline \multirow[t]{2}{*}{ Bacterial resistance } & Number of PNSP isolates/tested isolates (RES) & 11.25 & 10.99 & 0.00 & 48.00 \\
\hline & Number of MRSA isolates/tested isolates (RES1) & 18.78 & 15.95 & 0.20 & 50.00 \\
\hline Infections & Mortality rate for infectious diseases (INF) & 6.70 & 3.64 & 2.00 & 20.10 \\
\hline Population density & Population $/ \mathrm{km}^{2}$ & 130.34 & 98.89 & 2.62 & 392.64 \\
\hline Country area & $\mathrm{Km}^{2}$ & 203,068 & 170,135 & 2,586 & 551,500 \\
\hline \multirow[t]{2}{*}{ Animal production } & Tons of cow's milk/1,000 & $7,091.39$ & $7,801.24$ & 113.00 & $28,723.90$ \\
\hline & Number of pigs $/ 1,000$ & $7,045.43$ & $7,615.61$ & 3.51 & $26,989.10$ \\
\hline \multirow[t]{2}{*}{ Use of fertilisers } & Tons $/ 1,000$ & 919,186 & $1,115,849$ & 15,852 & $4,988,800$ \\
\hline & & Number of coun & atries & & \\
\hline \multirow[t]{3}{*}{ GPs reimbursement } & Fee for service $\left(\mathrm{PGP}_{1}=1\right)$ & $4(1997-2000)$ & & & $5(2001-2005)$ \\
\hline & Salary $\left(\mathrm{PGP}_{2}=1\right)$ & 7 (1997-2000) & & & $6(2001-2005)$ \\
\hline & Capitation & & 10 & & \\
\hline \multirow[t]{2}{*}{ Copayment } & Full/partial reimbursement & & 17 & & \\
\hline & Full out of pocket $(\mathrm{DCOP}=1)$ & & 4 & & \\
\hline \multirow[t]{4}{*}{ Regional clusters } & West & & 6 & & \\
\hline & East $\left(\mathrm{REG}_{\mathrm{e}}=1\right)$ & & 4 & & \\
\hline & North $\left(\mathrm{REG}_{\mathrm{n}}=1\right)$ & & 7 & & \\
\hline & South $\left(\mathrm{REG}_{\mathrm{s}}=1\right)$ & & 4 & & \\
\hline
\end{tabular}

Data sources: ESAC, EARSS, OECD, Eurostat, and European Observatory of Health Systems and Policies

$D D D$ defined daily doses, $D I D$ defined daily doses per 1,000 inhabitants per day, GDP gross domestic product, $P P P$ purchasing power parity, PNSP penicillin non-susceptible Streptococcus pneumoniae, MRSA methicillin-resistant Staphylococcus aureus

and the system of remuneration), incidence of bacterial infections (mortality rates), price and copayments, and levels of bacterial resistance.

Data were obtained from a variety of sources. Information on per capita income (measured in US dollars in purchasing power parity), density of physicians, the level of education and the incidence of infections were extracted from publications by the OECD (2007). The demographic structure of the population was derived from Eurostat tables (Eurostat 2007). From the yearly country profiles published by the European Observatory on Health Systems and Policies (2007), we collected information on the main type of payment system on hold for general practitioners (fee for service, capitation and salary).
We derived price levels for antibiotics during 20002005 by combining information from two indicators: the comparative price level index (PLI) and the harmonised annual average price index (HICP) for pharmaceutical products. The PLI indicates the price level of each country compared to the average price level of the $25 \mathrm{EU}$ countries in 2005. The HICP includes information on price trends for pharmaceuticals for each country during 2000 and 2005, where $2005=100$. These indices are provided by Eurostat (2007).

For the levels of bacterial resistance, data were obtained from the European Surveillance on Antimicrobial Resistance (EARSS) database (European Antimicrobial Resistance Surveillance System 2007). Routine antimicrobial 
susceptibility tests on invasive isolates of Streptococcus pneumoniae and Staphylococcus aureus are collected by participating laboratories in each country and submitted to EARSS. We neglected possible bias in the comparison of susceptibility data between countries that may be due to differences in case mix and hospital specialties, or introduced as a result of different laboratory routines between countries. The time span of the analysis was short because the data on bacterial resistance were available only after the systematic collection of bacterial resistance across European countries started recently (from 1999/2000).

Finally, information on instruments for infections and bacterial resistance (production of milk and meat of pigs, use of fertilisers, population density and country area) were obtained from Eurostat statistics (Eurostat 2007). This information was supplemented with data directly drawn from national statistics.

\section{Results}

The parameter estimates of the three models are summarised in Table 2. The results were stable and no structural difference was observed across the models. The time trend $(t)$ did not show any significant increase in the use of outpatient antibiotics per capita over time.

The responsiveness of the per capita outpatient antibiotic use to a $1 \%$ change in the average national income, ceteris paribus, was between 0.49 and $0.77 \%$.

The level of education reduced antimicrobial consumption significantly at less than $10 \%$ only in Model 2. A similar impact was observed for women participation in the labour market. In Model 1 and 2, a 1\% increase in women participation reduced antibiotic consumption by 0.57 and $0.67 \%$.

The effect of regional covariates was unclear. Generally, the coefficients were not significant with the exception of the northern region.

As for demographic covariates, we observed an association between the proportion of individuals aged 14 25 years and increasing levels of antimicrobial consumption. The impact of individuals below 14 years was also positive, although not highly significant. Finally, we found a significant association between the proportion of the population aged 65-79 years and increasing antimicrobial use in all the three models.

The physician density had a positive and significant effect in all three estimations. A $1 \%$ increase in physician density was associated with an increase in antibiotic use between 0.52 and $0.86 \%$. Covariates $\mathrm{PGP}_{1}$ and $\mathrm{PGP}_{2}$ associated with payment schemes for physicians were also significant in Model 1 and 2. The coefficients of these regressors indicated that the fee-for-service remuneration and the salary remuneration were related to higher levels of antibiotic use per capita compared to the capitation reimbursement.

The effect of antibiotic price was captured by means of two covariates: the price of a daily dose and patient copayment. We found that price elasticity exhibited the expected negative sign in all the three models, but only in Model 3 it was significant at less than $10 \%$. Consequently, price was associated with a lower antimicrobial consumption. Also, the impact of copayment had the expected negative sign. This means that purchasing antibiotics out of pocket instead of under total or partial reimbursement was associated with lower antimicrobial consumption.

Individual's health status measured by the mortality rate for infectious diseases was not significant in any of the regressions. Conversely, the association between antibiotic use and bacterial resistance measured by the proportion of penicillin non-susceptible Streptococcus pneumoniae isolates (PNSP) was positive and highly significant in all the three model specifications. A $1 \%$ increase in the level of bacterial resistance induced an increase in antibiotic consumption between 0.09 and $0.18 \%$. The higher values of estimated elasticities were obtained when endogeneity of bacterial resistance was taken into account. Very similar results were found in additional regressions using the methicillin-resistant Staphylococcus aureus (MRSA) indicator instead of PNSP.

\section{Discussion}

The investigation of socioeconomic determinants of antibiotic use may contribute to the discussion on effective government interventions to induce efficient use of drugs. Using an econometric approach, we showed that differences in outpatient antibiotic use across countries can hardly be explained by epidemiological, demographic and cultural factors only. Supply-side factors appear to play an important role. Indeed, higher levels of antibiotic use per capita were associated with higher density of doctors and a fee-for-service remuneration scheme.

The impact of income suggests that richer countries in Europe use more outpatient antibiotics compared to countries with lower ability to pay. The result conjectures that antimicrobials are normal goods. This means that income may contribute to greater access to medical care. Many studies have emphasised the role of income in explaining inequalities in health, health-care and preventive care utilisation. Recent evidence indicated, for instance, that income was associated to larger inequalities in the use of health-care services compared to educational level, although differences were smaller and less consistent with regard to primary care (Habicht et al. 2009). As for the use 
Table 2 Parameter estimates for the three models of outpatient antibiotic use in Europe

\begin{tabular}{|c|c|c|c|c|c|c|}
\hline & Model 1 & & Model 2 & & Model 3 & \\
\hline & Random-effects GLS & & Random-effects GLS & & Random-effects 2 SLS & \\
\hline & Obs. 81 & & Obs. 83 & & Obs. 81 & \\
\hline & Wald $\chi^{2}$ (18) $577.06^{\mathrm{d}}$ & & Wald $\chi^{2}(18) 651.25^{\mathrm{d}}$ & & Wald $\chi^{2}$ (17) $489.91^{\mathrm{d}}$ & \\
\hline & $R^{2}$ (overall) 0.9030 & & $R^{2}$ (overall) 0.9105 & & $R^{2}$ (overall) 0.8854 & \\
\hline Variables & Coeff. & Std. Err. & Coeff. & Std. Err. & Coeff. & Std. Err. \\
\hline Constant & $-9.013965^{\mathrm{b}}$ & 4.147910 & $-7.711871^{\mathrm{a}}$ & 3.938099 & $-10.601980^{\mathrm{b}}$ & 4.586670 \\
\hline$Y$ & $0.493317^{\mathrm{c}}$ & 0.169266 & $0.537290^{\mathrm{d}}$ & 0.126512 & $0.768270^{\mathrm{d}}$ & 0.210580 \\
\hline $\mathrm{POP}_{1}$ & $1.034719^{\mathrm{a}}$ & 0.587203 & 0.474416 & 0.361204 & 0.309970 & 0.695105 \\
\hline $\mathrm{POP}_{2}$ & $1.019814^{\mathrm{c}}$ & 0.338523 & $1.332917^{\mathrm{d}}$ & 0.296425 & $0.813798^{\mathrm{b}}$ & 0.377604 \\
\hline $\mathrm{POP}_{4}$ & $2.059900^{\mathrm{d}}$ & 0.501518 & $1.731337^{\mathrm{d}}$ & 0.447270 & $1.684739^{\mathrm{c}}$ & 0.568016 \\
\hline $\mathrm{POP}_{5}$ & $-0.580178^{\mathrm{b}}$ & 0.254358 & -0.221079 & 0.233545 & $-0.702093^{b}$ & 0.285032 \\
\hline EDU & -0.102868 & 0.207496 & $-0.335113^{\mathrm{b}}$ & 0.170047 & 0.010325 & 0.232368 \\
\hline EMPW & $-0.568037^{\mathrm{b}}$ & 0.276119 & $-0.671807^{\mathrm{b}}$ & 0.278283 & -0.086852 & 0.349315 \\
\hline $\mathrm{REG}_{\mathrm{e}}$ & -0.029618 & 0.156117 & 0.152904 & 0.130563 & 0.065643 & 0.174499 \\
\hline $\mathrm{REG}_{\mathrm{n}}$ & $0.250409^{\mathrm{b}}$ & 0.111997 & $0.216708^{\mathrm{b}}$ & 0.088739 & $0.411544^{\mathrm{c}}$ & 0.136410 \\
\hline $\mathrm{REG}_{\mathrm{s}}$ & 0.013515 & 0.231403 & -0.173561 & 0.190079 & 0.065756 & 0.256627 \\
\hline DPH & $0.587096^{\mathrm{c}}$ & 0.209351 & $0.519010^{\mathrm{c}}$ & 0.178472 & $0.863128^{\mathrm{c}}$ & 0.250119 \\
\hline $\mathrm{PGP}_{1}$ & $0.265965^{\mathrm{d}}$ & 0.065966 & $0.310308^{\mathrm{d}}$ & 0.056701 & 0.123090 & 0.089420 \\
\hline $\mathrm{PGP}_{2}$ & $0.197289^{c}$ & 0.062775 & $0.237605^{\mathrm{d}}$ & 0.059472 & 0.075278 & 0.082179 \\
\hline$P_{\mathrm{t}}$ & -0.281583 & 0.198971 & -0.045545 & 0.167865 & $-0.391798^{\mathrm{a}}$ & 0.221178 \\
\hline DCOP & -0.065513 & 0.065616 & -0.045444 & 0.057407 & -0.121759 & -0.074834 \\
\hline $\mathrm{INF}_{\mathrm{t}}$ & -0.001800 & 0.057033 & - & - & 0.119956 & 0.081094 \\
\hline $\mathrm{INF}_{t-1}$ & - & - & -0.079473 & 0.049525 & - & - \\
\hline $\mathrm{RES}_{t}$ & $0.092181^{\mathrm{c}}$ & 0.026898 & - & - & $0.181727^{\mathrm{d}}$ & 0.044038 \\
\hline $\operatorname{RES}_{t-1}$ & - & - & $0.088619^{\mathrm{d}}$ & 0.022522 & - & - \\
\hline$t$ & 0.002920 & 0.017395 & -0.007144 & 0.012309 & -0.028560 & 0.022243 \\
\hline$\sigma_{k}$ & & 0 & & 0 & & 0 \\
\hline$\sigma$ & & 0.041464 & & 0.063106 & & 0.107441 \\
\hline$\rho$ & & 0 & & 0 & & 0 \\
\hline
\end{tabular}

$G L S$ generalised least squares, $2 S L S$ two-stages least squares, $Y$ income per capita, $P O P_{1}$ population under 14 years, $P O P_{2}$ population at 15-24 years, $\mathrm{POP}_{4}$ population at 65-79 years, $P O P_{5}$ population over 80 years, $E D U$ attainment of high education, $E M P W$ women participation in the labour market, $R E G_{e}$ western Europe, $R E G_{n}$ northern Europe, $R E G s$ southern Europe, $D P H$ density of doctors, $P G P_{l}$ fee-for-service GPs reimbursement, $P G P_{2}$ salary-based GPs remuneration, $P_{t}$ antibiotic price, $D C O P$ no patient copayment (full out of pocket), $I N F_{t}$ mortality due to infectious diseases, $I N F_{t-1}$ mortality due to infectious diseases lagged 1 year, $R E S_{t}$ bacterial resistance, $R E S_{t-1}$ bacterial resistance lagged 1 year, $t$ time trend

$\sigma_{k}$ standard deviation of common residuals, $\sigma_{\varepsilon}$ standard deviation of unique (individual) residuals, $\rho$ variance not explained by differences across entities

${ }^{a}$ Significant at $10 \%,{ }^{b}$ significant at $5 \%,{ }^{\mathrm{c}}$ significant at $1 \%,{ }^{\mathrm{d}}$ significant at $0.1 \%$

of antimicrobials, our income elasticity was lower than the value observed by Baye et al. (1997) using US data (1.33) but higher than findings observed by Filippini et al. (2006) on regional Swiss data $(-0.5)$.

To our knowledge, there are no comparable multivariate studies on the impact of education on the use of antibiotics. A comparison with the literature on medical-care utilisation indicates that antibiotics are quite peculiar. Hunt-McCool et al. (1994) found positive education elasticity to physician office visits and hospital care, although the impact was not very significant. People with low education may perceive lower utility or higher costs of medical care. Conversely, more highly educated people may be more informed about health care and therefore more prone to undergo a treatment. In the case of antibiotics, our result suggests that educated individuals may restrain from using antibiotics because they are more concerned about the implications of bacterial resistance compared to other individuals. 
Evidence on the effect of women participation in the labour market suggests similar conclusions. On one hand, women participating in the labour market are likely to face high opportunity cost of time and, consequently, may be inclined to use antibiotics more frequently than other women. On the other hand, women participating in the labour market may be more informed and more keen on using antibiotics carefully. In general, evidence on the role played by occupational aspects in affecting health behaviour across countries remains weak. For instance, strong association was recently found between parental occupation and vegetable consumption and TV viewing amongst adolescents, whereas no association was found between parental occupation and tobacco and alcohol use amongst adolescents (Richter et al. 2009).

Regional covariates in our models do not seem to explain differences in antibiotic use across Europe when socioeconomic determinants are taken into account. We found only weak evidence that northern regions use more antibiotics than western regions, ceteris paribus. Although, on average, antibiotic use between 2000 and 2005 was lower in northern Europe (16.98 DID vs. 19.39 DID), the northern covariate suggests that this was mainly explained by differences in socioeconomic aspects.

The literature on determinants of health-care expenditure generally suggests that the increasing prevalence of chronic health problems as people grow older may determine an increase in the utilisation of health-care services. The positive and significant effect of the proportion of the population between 65 and 79 found in our regressions seems to support this hypothesis. Di Matteo and Grootendorst (2002) also observed a slightly significant increase in drug expenditure in the population between 64 and 74, although the result was not confirmed by the more recent study by Di Matteo (2005). Moreover, because of major health problems, individuals in the last few years of life may be more likely to consume antibiotics in nursing homes or hospital clinics rather than get them prescribed in outpatient care. Indeed, we observed that individuals older than 80 years seemed to reduce their per capita consumption of outpatient antibiotics.

The positive effect of physician density might put forward some evidence of supply-induced demand. Moreover, we found evidence on the impact of payment schemes for physicians, which is in accordance with the hypothesis on financial incentives generated by these schemes. Under feefor-service remuneration, doctors' revenue is usually related to the number and the time of consultations. This may imply a positive relationship with the amount of prescriptions, though not straightforwardly. Doctors may then be prone to meet patients' preferences for antibiotic treatment since the risk of losing disappointed patients immediately after a consultation is higher compared to the capitation scheme. Conversely, under a capitation scheme, doctors may have less incentive to prescribe antibiotics. This is because the quality of treatment is not directly related to the quantity of antibiotics prescribed, but may improve with doctor's ability to induce patient's compliance and to reduce inappropriate antibiotic use. Similarly to the fee for service, salaried practitioners may lack incentives to restrain from prescribing antibiotics.

Generally, antibiotics are perceived as necessary in the case of presumed bacterial infections. Since antibiotics are purchased under doctor's prescription, their demand may not be very elastic to the price, as suggested by our estimations. Clearly, this depends on the share of price borne directly by the patient. Nevertheless, low levels of copayments may not be very successful in discouraging individuals from using antibiotics if these are perceived as necessary. Looking at prices for anti-infectives, Baye et al. (1997) found negative compensated $(-0.785)$ and uncompensated $(-0.916)$ own-price effects. Focusing on the demand for one antibiotic class, the cephalosporins, Ellison et al. (1996) calculated own-price elasticities for different brand/generic names unconditional of drug expenditure using US wholesale data from 1985 to 1991. Their estimates ranging from -0.38 to -4.34 and were close to our result ( -0.39 in Model 3). The fact that the impact of copayments was not significant in our regressions may suggest that individuals were not very responsive to changes in the cost of drugs, since these may be perceived as necessary under uncertainty of the nature of infections.

The coefficients of the rate of mortality suggest that outpatient antibiotic expenditure is not very elastic to the impact of epidemiological factors. Note, however, that seasonal epidemic effects are not considered since we focused on annual consumption of antibiotics. We obtained similar results by using mortality for pneumonia and influenza instead of mortality for infectious diseases. Data available for the former variable were fewer and reduced the number of observations in our estimations. Looking at the pharmaceutical consumption for cardiovascular disease and stroke, Dickson and Jacobzone (2003) found that drug use was strongly related to indicators of the burden of disease only for more effective and inexpensive types of drugs.

The role of bacterial resistance might be underestimated by Models 1 and 2 if resistance was endogenous. Tests for endogeneity such as the Durbin test and the Wu-Hausman test suggested that we could not easily reject the hypothesis that all covariates were exogenous. Consequently, from a statistical point of view the results in Model 3 cannot be preferred to those obtained in Model 1 and 2. However, the link between bacterial resistance and aspects such as meat production, the use of fertilisers in agriculture and the density of the population was generally hypothesised in 
literature. Since correlation between these potential determinants of bacterial resistance and antibiotic use was very weak, it was straightforward to propose a model specification (Model 3) that could strengthen our results.

One possible limitation of our approach is the lack of general indicators for bacterial resistance and the consequent use of specific indicators such as PNSP and MRSA. Clearly, these indicators can only be partially associated with total antibiotic use, but yet represents valid information for the overall magnitude of bacterial resistance in a country.

Increasing levels of bacterial resistance represent a harmful challenge for the society (Rudholm 2002). Several studies showed that changes in antimicrobial use may be followed by changes in antimicrobial resistance (Bergman et al. 2004; Stephenson 1996). Moreover, bacterial resistance may result in (1) an increased antibiotic use of the more recently available antibiotics (such as the later fluoroquinolones) and/or (2) an increased dosage of the old classes of antibiotics to overcome resistance against these antibiotics (such as amoxicillin and amoxicillin/clavulanic acid) (Austin et al. 1999; Albrich et al. 2004; Filippini et al. 2009b; Woodhead et al. 2005). The former effect may have a minor impact on the volume of use if it reflects the substitution of old by new antibiotics only. The latter may result in a substantial increase of the number of doses. In both cases, the number of doses may increase through the number of prescriptions if there are more treatment failures associated with resistance and the need for retreatment, possibly with increased dosage or alternative antibiotics.

The purpose of reducing the future social costs of poor antibiotic effectiveness could also lead to a decrease in the use of antibiotics. Nevertheless, it is not possible to say whether or not awareness of resistance by doctors, patients and policy makers would result in lower rates of antibiotic use. This is because antibiotic treatment with existing information may still be the best possible solution for the patient even though it produces disappointing results in terms of bacterial resistance.

We estimated that bacterial resistance has a positive and significant impact on the number of antimicrobial administrations, although the responsiveness is relatively low. The effects of public campaigns for promoting careful use of antibiotics in outpatients were not directly included in our models. Recently, Huttner et al. (2010) found some evidence that public campaigns reduced antibiotic use, but their effects on bacterial resistance could not be accurately assessed. The relatively low responsiveness of antibiotic use to increasing levels of bacterial resistance found in our models could then suggest that public campaigns have partially mitigated the impact of bacterial resistance on antibiotic consumption in recent years. Further research would help to disentangle this relationship.
Acknowledgments We are grateful to the ESAC Project Group members: Helmut Mittermayer, Sigrid Metz (Austria); Boyka Markova (Bulgaria); Arjana Andrasevic, Igor Francetic (Croatia); Despo Bagatzouni (Cyprus); Jiri Vlcek (Czech Republic); Dominique L. Monnet, Annemette Anker Nielsen (Denmark); Ly Rootslane (Estonia); Pentti Huovinen, Pirkko Paakkari (Finland); Philippe Cavalié, Didier Guillemot (France); Winfried Kern, Helmut Schroeder (Germany); Helen Giamarellou, Anastasia Antoniadou (Greece); Gabor Ternak (Hungary); Karl Kristinsson (Iceland); Robert Cunney, Ajay Oza (Ireland); Raul Raz (Israel); Giuseppe Cornaglia (Italy); Sandra Berzina (Latvia); Rolanda Valenteliene (Lithuania); Robert Hemmer, Marcel Bruch (Luxembourg); Michael Borg, Peter Zarb (Malta); Robert Janknegt, Margreet Filius (the Netherlands); Hege Salvesen Blix (Norway); Waleria Hryniewicz, Pawel Grzesiowski (Poland); Luis Caldeira (Portugal); Irina Codita (Romania); Leonid Stratchounski (deceased June 7, 2005), Svetlana Ratchina (Russia); Viliam Foltan, Tomas Tesar (Slovakia); Milan Cizman (Slovenia); José Campos (Spain); Otto Cars, Gunilla Skoog, Sigvard Mölstad (Sweden); Serhat Unal (Turkey); Peter Davey (UK). The paper reflects the views of the authors only.

Conflict of interest statement The authors declare that they have no competing interests.

Open Access This article is distributed under the terms of the Creative Commons Attribution Noncommercial License which permits any noncommercial use, distribution, and reproduction in any medium, provided the original author(s) and source are credited.

\section{References}

Albrich W, Monnet D, Harbarth S (2004) Antibiotic selection pressure and resistance in Streptococcus pneumoniae and Streptococcus pyogenes. Emerg Infect Dis 10:514-517

Austin DJ, Kristinsson KG, Anderson RM (1999) The relationship between the volume of antimicrobial consumption in human communities and the frequency of resistance. Proc Natl Acad Sci USA 96:1152-1156

Baltagi BH (2005) Econometric analysis of panel data. Wiley, Chichester, West Sussex

Baye MR, Maness R, Wiggins SN (1997) Demand systems and the true subindex of the cost of living for pharmaceuticals. Appl Econ 29:1179-1189

Belongia EA, Schwartz B (1998) Strategies for promoting judicious use of antibiotics by doctors and patients. Brit Med J 317:668671

Bergman M, Huikko S, Pihlajama M, Laippala P, Palva E, Huovinen P, Seppala H (2004) Effect of macrolide consumption on erythromycin resistance in Streptococcus pyogenes in Finland in 1997-2001. Clin Infect Dis 38:1251-1256

Butler C (2008) Sustainable health for all by the year 2100? Int J Public Health 53:223-224

Cameron AC, Trivedi PK (2005) Microeconometrics. Cambridge University Press, New York

Cockburn J, Pit S (1997) Prescribing behaviour in clinical practice: patients' expectations and doctors' perceptions of patients' expectations-a questionnaire study. Brit Med J 315:520-523

Di Matteo L (2005) The macro determinants of health expenditure in the United States and Canada: assessing the impact of income, age distribution and time. Health Policy 71:23-42

Di Matteo L, Grootendorst P (2002) Federal patent extension, provincial policies, and drug expenditures, 1975-2000. Can Tax J 50:1913-1948 
Dickson M, Jacobzone S (2003) Pharmaceutical use and expenditure for cardiovascular disease and stroke: a study of 12 OECD countries. OECD Health Working Papers 1

Donaldson C, Gerard K, Mitton C, Jan S, Wiseman V (2004) Economics of health care financing: the visible hand. Thomas Palgrave MacMillan, London

Elbasha EH (2003) Deadweight loss of bacterial resistance due to overtreatment. Health Econ 12:125-138

Ellison SF, Cockburn I, Griliches Z, Hausman J (1996) Characteristics of demand for pharmaceutical products: an examination of four cephalosporins. Rand J Econ 28:426-446

Elsevier M, Ferech M, Vander Stichele RH, Goossens H (2007) Antibiotic use in ambulatory care in Europe (ESAC data 19972002): trends, regional differences and seasonal fluctuations. Pharmacoepidem Dr S 16:115-123

European Antimicrobial Resistance Surveillance System (2007) EARSS interactive database. http://www.rivm.nl/earss/database. Accessed December 2007

European Observatory on Health Systems and Policies (2007) Health system profiles (HiTs). http://www.euro.who.int/en/home/projects/ observatory/publications/health-system-profiles-hits. Accessed December 2007

Eurostat (2007) Eurostat statistics. http://epp.eurostat.ec.europa.eu/ portal/page/portal/statistics/ themes. Accessed December 2007

Filippini M, Masiero G, Moschetti K (2006) Socioeconomic determinants of regional differences in outpatient antibiotic consumption: evidence from Switzerland. Health Policy 78:77-92

Filippini M, Masiero G, Moschetti K (2009a) Small area variations and welfare loss in the use of outpatient antibiotics. Health Econ Pol Law 4:55-77

Filippini M, Masiero G, Moschetti K (2009b) Regional consumption of antibiotics: a demand system approach. Econ Model 26:13891397

Finch RG, Metlay JP, Davey PG, Baker LL (2004) Educational interventions to improve antibiotic use in the community: report from the international forum on antibiotic resistance (IFAR) colloquium. Lancet 4:44-53

Goossens H, Ferech M, Vander Stichele R, Elseviers M (2005) Outpatient antibiotic use in Europe and association with resistance: a cross-national database study. Lancet 365:579-587

Greene WH (2003) Econometric analysis. Prentice Hall, New York

Habicht J, Kiivet RA, Habicht T, Kunst AE (2009) Social inequalities in the use of health care services after 8 years of health care reforms - a comparative study of the Baltic countries. Int $\mathrm{J}$ Public Health 54:250-259

Hoogendijk E, van Groenou MB, van Tilburg T, Deeg D (2008) Educational differences in functional limitations: comparison of 55-65-years-olds in the Netherlands in 1992 and 2002. Int J Public Health 53:281-289

Hunt-McCool J, Kiker BF, Ng YC (1994) Estimates of the demand for medical care under different functional forms. J Appl Econ 9:201-218

Huttner B, Goossens H, Verheij T, Harbarth S (2010) Characteristics and outcomes of public campaigns aimed at improving the use of antibiotics in outpatients in high-income countries. Lancet Infect Dis 10:17-31

İlhan IOO, Yıldırım F, Demisbaş H, Doğan YB (2009) Prevalence and sociodemographic correlates of substance use in a universitystudent sample in Turkey. Int J Public Health 54:40-44

Kunst AE (2009) Socioeconomic inequalities in health in Central and Eastern Europe: synthesis of results of eight new studies. Int $\mathbf{J}$ Public Health 54:197-200

Matuz M, Benko R, Doro P, Hajdu E, Nagy G, Nagy E, Monnet DL, Soos $G$ (2006) Regional variations in community consumption of antibiotics in Hungary, 1996-2003. Br J Clin Pharmacol 61:96-100

McGowan JE (2001) Economic impact of antimicrobial resistance. Emerg Infect Dis 7:286-292

OECD (2007) OECD Health Data 2007. http://titania.sourceoecd.org/ $\mathrm{vl}=1037283 / \mathrm{cl}=48 / \mathrm{nw}=1 / \mathrm{rpsv} / \mathrm{statistic} / \mathrm{s} 37 \_$about.htm?jnlissn= 99991012. Accessed December 2007

Richter M, Vereecken CA, Boyce W, Maes L, Gabhainn SN, Currie CE (2009) Parental occupation, family affluence and adolescent health behavior in 28 countries. Int J Public Health 54:203-212

Rudholm N (2002) Economic implications of antibiotic resistance in a global economy. J Health Econ 21:1071-1083

Stephenson J (1996) Icelandic researchers are showing the way to bring down rates of antibiotic-resistant bacteria. JAMA-J Am Med Assoc 275:175

Swiss National Science Foundation (2007) National Research Programme NRP 49 Antibiotic Resistance Final Report. http://www.nrp49.ch/upload/docs/Dokumente/NRP_49_Report_ WEB\%20mit\%20Links.pdf. Accessed December 2007

Thomas RL (1987) Applied demand analysis. Longman, London

Vander Stichele R, Elseviers M, Ferech M, Blot S, Goossens H (2004) European surveillance of antimicrobial consumption (ESAC): data collection performance and methodological approach. Br J Clin Pharmacol 58:419-428

Woodhead M, Blasi F, Ewig S, Huchon G, Leven M, Ortqvist A, Schaberg T, Torres A, van der Heijden G, Verheij TJM (2005) Guidelines for the management of adult lower respiratory tract infections. Eur Respir J 26:1138-1180 